\title{
PENGGUNAAN ALIH KODE DALAM PERCAKAPAN PADA JARINGAN WHATSAPP OLEH MAHASISWA KNB YANG BERKULIAH DI UNIVERSITAS SEBELAS MARET
}

\author{
Khodiyo Thesa \\ Universitas Sebelas Maret \\ khadijahthesa@gmail.com
}

\begin{abstract}
The aims of this research are (1) to find the types of code switching that used in what'sapp conversation by KNB students of Sebelas Maret University (2) to describe the factors of code switching by KNB students of Sebelas Maret University (3) to describe the functions of code switching by KNB students of Sebelas Maret University. This research is adescriptive qualitative research employing etnography method (analizing of domain, taxonomy, and componential) in order tofix the pattern of the culture theme. The source of data taken from the code switching conversations of KNB Students. The data are conversations of KNB students in Sebelas Maret University that joined in Sibling What'sApp Group from August until November 2016 and contain of code switching. The collecting data is conversation transcription in Sibling What'sApp group that relates with switching code. The research results were (1) the types of switching code that used by KNB students wereintersentencial switching, intrasentencial switching, and tag switching. The result of analizing research that refers to Spreadly theory or etnography theory showed that intrasentential was the dominan switching code that appear on KNB students conversation about $43 \%$ (2) the factors that caused $K N B$ students switching the code of on their conversation were speaker, addresse speaker, topic, situation, humor, ability, technology, familiarity, and relation whereas (3) the functions of switching codes on the KNB students conversations were to familiar between the speaker and address speaker, to respect the local culture they stayed, to make easy the communication, words of technology, to rich language ability, to remind something to address speaker, to respond the questions, to begin, middle and to end the conversations, to emphasize the speaker meaning, invitation, to change formal situation to informal, perception, to express the speaker feeling, to quote the other person conversation, humor, to address specification, to ask a help, to explain the speaker meaning, and to change a topic. The result of this research showed that switching code on KNB students conversation that join on Sibling What's App group had three types and it had the factors that can influence switching code and for each KNB students conversation had the function. Intrasentencial code is the dominan switching code because KNB students often use the switching code in words or phrase form.
\end{abstract}

Keywords: KNB students, code switching, intersentential switching, intrasentential switching, tag. 


\section{Pendahuluan}

Bahasa merupakan alat komunikasi yang berupa sistem lambang bunyi yang menjadi alat ucap manusia. Komunikasi mempunyai definisi berupa suatu sistem yang dimiliki oleh manusia dalam kegiatan sehari-hari. Meskipun dalam kegiatan komunikasi tertulis sebagian besar menggunakan bahasa nasional tapi dalam komunikasi antar suku, bahasa daerah merupakan peranan yang sangat penting dalam komunikasi antar masyarakat. Bahasa daerah sering dipakai sebagai penyampaian ilmu pengetahuan di lembaga-lembaga yang berkaitan dengan kehidupan masyarakat seperti Agama dan Budaya. Masyarakat yang menggunakan dua bahasa atau lebih dalam berbicara disebutkan masyarakat bilingual dan multilingual. Sementara itu, bahasa tidak hanya dalam percakapan bertatap muka saja, seiring dengan berkembangnya teknologi, percakapan melalui media komunikasi baru yang lebih maju. Alat komunikasi yang belakangan ini sedang populer ialah media sosial di internet. Dengan sebuah microblog, yang bernama WhasApp. Komunikasi tanpa bertatapan langsung, dengan menggunakan pesan tertulis bisa menyampaikan ujaran dan pesan berinteraksi, dan melakukan percakapan dengan orang lain. Salah satu group mahasiswa asing yang berkuliah di Universitas Sebelas Maret yaitu mahasiswa Kemitraan Negara Berkembang (KNB). Mahasiswa luar negeri ini datang dari berbeda negara yang mempunyai berbagai bahasa. Namun Bahasa Inggris adalah bahasa pengantar pertama bagi mereka tapi bila mereka tinggal di Indonesia dan berkuliah mereka akan dapat pengaruh dari beberapa bahasa seperti Bahasa Indonesia, Bahasa Jawa atau Bahasa daerah lain. Penggunaan bahasa bagi mahasiswa KNB merupakan percakapan alih kode berdasarkan bahasa pengantar pertama (Bahasa Inggris) dan bahasa kedua (Bahasa Indonesia atau bahasa daerah). Berdasarkan latar belakang dan penelitian yang sudah dilakukan sebelum ini saya dikemukakan, rumusan masalah yang akan dibahas dalam penelitian ini adalah berikut. 1) Apakah jenis alih kode yang digunakan lewat WhatsApp oleh mahasiswa KNB dari UNS? 2) Faktor-faktor apa yang menyebabkan mahasiswa KNB dari UNS menggunakan alih kode? 3) Apakah fungsi alih kode dalam percakapan lewat WhatsApp oleh mahasiswa KNB dari UNS? Penelitian ini bertujuan penelitian ini sebagai berikut. 1) Menemukan jenis alih kode yang digunakan dalam percakapan lewat WhatsApp Mahasiswa KNB dari UNS. 2) Mendeskripsikan faktor-faktor penyebab alih 
kode oleh mahasiswa KNB dari UNS. 3) Mendeskripsikan fungsi dalam alih kode lewat WhatsApp oleh mahasiswa KNB dari UNS.

Poplack (1980), dalam Romaine, 1989: 112) alih kode terdiri dari tiga jenis yaitu, tag switching, intersentensial, dan intrasentensial. Tag switching adalah jenis yang tergolong dalam satuan elemen bebas yang terdapat dalam bahasa pada sebuah kalimat pertanyaan atau pernyataan yang biasanya terletak di awal atau akhir kalimat. Intrasentensial Switchingmenurut (Appel \& Muysken 1987, dalam Nahdiah, 2012) menyebutkan bahwa intrasentensial switching occurs within a sentence or a clause'.Alih kode intrasentensial terjadi dalam sebuah kalimat atau sebuah klausa'. Biasanya ditemukan dalam bentuk kata atau frasa. Intersentensial Switching menurut Poplack (1980) dalam Hendar dan Tina Sesar Yunita (2012) " this is the most complex type of code switching because the speaker has to control two linguistic system simultaneously." Intersentensial switching adalah jenis yang paling jarang digunakan karena dibutuhkan keluwesan bagi pembicara untuk dapat berbicara dalam dua bahasa sekaligus dalam bentuk yang lebih kompleks yaitu dalam bentuk klausa atau kalimat. Berkaitan dengan alih code (code switching) ini, Chaer and Agustina (2010: hal. 120) menjelaskan bahwa alih kode adalah penggantian bahasa atau ragam bahasa oleh seorang penutur dalam kaadaan tertentu dangan sadar. Menurut Poplack (1980), dalam Romaine (1989: hal. 112) alih kode terdiri dari tiga jenis yaitu, tag switching, intersentensial, dan intrasentensial.Tag switching adalah jenis tergolong dalam satuan elemen bebas yang terdapat dalam bahasa pada sebuah kalimat pertanyaan atau pernyataan. Contoh Tag switching yangtermasuk ke dalam discourse markers adalah you know, I mean, by the way, hi, okay, dan lain. Intrasentensial Switchingmenurut (Appel \& Muysken 1987,dalam Nahdiah, 2012) menyebutkan bahwa Intrasentensial switching occurs within a sentence or a clause 'Intrasentensial terjadi pada sebuah kalimat atau sebuah klausa'. Biasanya ditemukan dalam bentuk kata atau frasa.Intersentensial Switching menurut Poplack mengatakan "this is the most complex type of code switching because the speaker has to control two linguistic system simultaneously" hal ini merupakan tipe alih kode yang paling kompleks karena penutur harus mengendalikan dua sistem bahasa secara bersamaan. Intersentensial switching adalah jenis alih kode yang membutuhkan keluwesan bagi pembicara untuk dapat berbicara dalam dua bahasa sekaligus dalam bentuk yang lebih kompleks yaitu dalam 
bentuk klausa atau kalimat. (Hendar dan Tina Sesar Yunita2012: 117). Lebih lanjut, faktor penyebab terjadinya alih kode dalam masyarakat tertentu dapat disebabkan oleh beberapa hal. Selain sikap kemultibahasaan yang dimiliki oleh masyarakat tutur, terdapat beberapa faktor yang menyebabkan terjadinya peristiwa alih kode, seperti latar belakang. Chaer dan Agustina (2010: hal. 108), menyebutkan bahwa faktor penyebab terjadi antaranya yaitu: 1) Penutur, 2) Mitra tutur, 3) Hadirnya penutur ketiga, 4) Perubahan situasi, 5) Topik pembicaraan.

Suandi (2014) menyatakan alih kode adalah pemakaian bahasa atau kode itu masih mendukung fungsinya sendiri-sendiri sesuai dengan isi (konteks) yang dipendamnya. Sementara itu, Ritchie dan Bhatio (1996: hal. 659-662) dalam Nahdiah (2012) mengelompokkan fungsi alih kode menjadi beberapa jenis, yakni; 1)Kutipan (quotation), 2) Spesifikasi Lawanbicara (addressee specification), 3) Interjeksi atau pelengkap kalimat (interjection or sentence filler), 4) Pengulangan pernyataan (reiteration), 5) Penjelas pesan (message qualification).

\section{Teori dan Metodologi Penelitian}

Penelitian ini merupakan sebuah penelitian deskriptif kualitatif. Penelitian deskriptif ini bertujuan untuk mengungkapkan berbagai informasi kualitatif dengan pendeskripsian yang teliti dan nuansa untuk menggambarkan secara individual atau kelompok, kejadian, gejala maupun fenomena (Sutopo, 2002: hal. 8-10). Penelitian ini diadakan di jaringan media sosial yaitu sebuah aplikasi pesan untuk handphone bernama WhatsApp.Jaringan WhatsApp ini dipilih karena penggunaan alih kode dalam jaringan ini dapat menggambarkan perilaku kebahasaan serta sikap dan pandangan para informan dalam situasi formal dan informal.

Sumber data dalam penelitian ini terdiri pada percakapan oleh mahasiswa KNB yang menggunakan alih kode, dan pustaka. Narasumbernya antara lain informan dari penutur L2 yaitu mahasiswa KNB di UNS dari angkatan 2012, 2013, 2014 dan 2015.

Data pada penelitian ini diperoleh dari dua data yaitu data primer dan data sekunder. Data primer dalam penelitian ini berupa percakapan yang mengandung alih kode dari mahasiswa KNB yang berkuliah di UNS yang berada dalam grup What'sApp Siblings dari bulan Agustus 2015 sampai dengan bulan November 2016. Sementara itu, data sekunder dalam penelitian ini adalah berupa informan yang diwawancara dengan 
teknik cakap bertemu muka, lewat WhatsApp dan Facebook yang dilakukan pada tanggal 28 sampai 29 Juli 2016. Lokasi dan waktu penelitian ini diadakan di jaringan media sosial yaitu sebuah aplikasi pesan untuk handphone bernama WhatsApp. Penelitian ini mengumpulkan data percakapan WhatsApp dari bulan Agustus 2015 sampai bulan Novemper 2016.

Berdasarkan rumusan masalah untuk mengetahui alih kode oleh mahasiswa KNB berdasarkan status sosial dalam WhatsApp. Langkah-langkah yang dilakukan penelitian dalam menyusun penelitian ini adalah: 1)Mengumpulkan percakapan WhatsApp group yang digunakan oleh mahasiswa KNB kemudian menyeleksikan percakapan WhatsApp yang berisi data alih kode di dalamnya. 2) Reduksi data untuk mendapatkan data-data yang masuk dalam ketegori penelitian, yakni tuturan yang mengandung unsur alih kode pada tuturan dalam WhatsApp. 3) Kemudian dilakukan transkripsi data secara ortografis pada data yang masuk dalam ketegori penelitian. 4) Pada transkripsi data ini, peneliti hanya mentranskripsikan hal-hal yang berhubungan dengan penelitian saja. Maksudnya adalah peneliti tidak mentranskripsikan semua hasil secara mendetail hal-hal yang tidak relevan, misal trenskripsi fonetik pada tuturan. 5) Setelah dilakukan transkripsi data langkah selanjutnya adalah pengelompokan ketegori data. 6) Menyimpulkan pola pemilihan kode kemudian dianlisis data berdasarkan jenisjenis alih kode dan mendeskripsinya. 7) Selanjutnya, mengelompokkan data dan dianalisis berdasarkan faktor-faktor terjadi alih kode dan mendeskripsinya. 8) Mengelompokkan anlisis data berdasarkan fungsi-fungsi alih kode dan mendeskripsinya. 9) Selanjutnya, melakukan wawancara mahasiswa KNB yang berkuliah di UNS dengan menggunakan metode cakap dan teknik memancing dan teknik bertemu muka dan lewat WhatsApp dan Facebook untuk minta komentar tentang penggunaan alih kode dalam percakapan (faktor dan fungsi dalam mengalih kode dalam tuturan yang muncul ketika mereka berbicara dalam WhatsApp. 10) Menganalisis bentuk penggunaan alih kode secara tidak terstruktur pada percakapan melalui WhatsApp yaitu tidak berdasarkan pada rincian pertanyaan yang kaku. 11) kode dalam lampiran mengaju pada kode MKNB bersingkat dari mahasiswa Kemitraan Negara Berkembang, nomor data, tanggal, bulan, dan waktu berlaku dalam WhatsApp.

Uji validitas data dilakukan untuk menguji keabsahan data yang terkumpul dan penguji hasil analisis. Ada empat macam tehnik triangulasi yang digunakan dalam 
penelitian kualitatif yaitu triangulasi sumber, triangulasi metode, traingulasi teori dan tiangulasi penelitian ( Linccoln \& Guba, 1985; Patton, 1980 dalm Santosa, 2012 )Pada penelitian ini digunakan dua teknik dalam triangulasi, yaitu triangulasi sumber dan triangulasi metode.

Triangulasi Sumber data adalah teknik menyediakan sumber data yang bervariasi. Sumber data pada penelitian ini dapat digunakan yaitu dokumen dan informan. Dari dokumen, dapat diperoleh sumber data seperti percakapan dari WhatsApp grup KNB Siblings. Dari informan, dapat digunakan sumber data yaitu mahasiswa KNB di UNS. Triangulasi metode adalah teknik mengumpulan data. Pada penelitian ini mengumpukan data melalui dua data yaitu data dari dokumen dan data dari informan. Data dokumen dapat diperoleh dengan teknik analisis dokumen.Data dari dokumen dalam penelitian ini berupa percakapan WhatsApp grup KNB Siblings. Data dari informan didapat dengan cara mewawancara beberapa informan. Pengaturan data dalam penelitian ini dilakukan dengan cara memilih dan mengatur secara fisik semua data ke dalam kelompok, folder atau kartu sesuai dengan rumusan masalah penelitian agar mudah digunakan untuk proses selanjutnya (Sutopo, 2002:87).

Secara interaktif (Sutopo,1990: hal. 28), yaitu reduksi data, sajian data, simpulan dilakukan secara bersamaan dengan proses pengumpulan data. Menurut Spradley (1980) dalam Santosa (2012) menyatakan bahwa ada empat komponen analisis data dalam sebuah penelitian, yakni analisis domain, anlisis taksonomi, analisis komponensial, dan tema budaya (finding cultural value).

\section{Hasil Penelitian dan Pembahasan}

Penelitian ini terdiri dari tiga rumusan masalah antara lain, jenis-jenis alih kode, faktor-faktor penyebab terjadi alih kode dan fungsi-fungsi yang terdapat dalam alih kode. Untuk lebih jelasnya peneliti akan membahas satu persatu dari rumusan masalah yang terdapat dalam bab sebelumnya.

\section{Jenis Alih Kode}

Tabel 1. Analisis Data Wujud Alih Kode

\begin{tabular}{|c|c|c|}
\hline Jenis & Jumlah & $\%$ \\
\hline Tag & 40 & $23 \%$ \\
\hline Intrasentential & 75 & $43 \%$ \\
\hline Intersentential & 58 & $34 \%$ \\
\hline Total & 173 & $100 \%$ \\
\hline
\end{tabular}


Dari tabel tersebut peneliti dapat mengambil simpulan bahwa peralihan kode yang paling dominan muncul adalah bentuk peralihan kode intrasentential dengan persentase $43 \%$ dari satuan lingual berupa kata dan frasa yang terlibat dalam klausa, dan kalimat sedangkan peralihan kode yang paling sedikit muncul adalah peralihan kode Tag dengan persentase $23 \%$ yang terdiri dari satuan lingual kata dan frasa.

\section{Faktor Penyebab Terjadinya Alih Kode}

Banyak faktor penyebab terjadinya alih kode. Menurut Suwito (1996: hal. 8587) ada beberapa faktor yang melatarbelakangi terjadinya alih kode. Pada penelitian ini akan dianalisis kemunculan faktor-faktor tersebut pada masing-masing jenis alih kode yang sering digunakan oleh para mahasiswa KNB dari UNS terdapat (1) Penutur (2) Mitra Tutur (3) Topik Pembicaraan (4) Situasi (5) Humor (6) Kemampuan (7) Teknologi (8) Keakraban dan (9) Hubungan. Faktor-faktor yang menyebabkan terjadinya alih kode dalam dialogpercakapan lewat WhatsApp oleh mahasiswa $\mathrm{KNb}$ terdapat pada tabel dan uraian data berikut ini.

Tabel 4 Faktor Terjadinya Alih Kode

\begin{tabular}{|c|c|c|c|c|c|c|}
\hline \multirow{2}{*}{ No } & \multirow{2}{*}{$\begin{array}{c}\text { Faktor } \\
\text { penyebab }\end{array}$} & $\mathbf{5 a g}$ & Intrasentential & Intersentential & \multirow{2}{*}{$\sum$} & \multirow{2}{*}{ Alih kode } \\
\cline { 3 - 7 } & Penutur & 26 & 32 & 31 & $\mathbf{8 9}$ & $\mathbf{5 1 \%}$ \\
\hline 2 & Mitra tutur & & 24 & & $\mathbf{2 4}$ & $\mathbf{1 4 \%}$ \\
\hline 3 & Topik & & 1 & 2 & $\mathbf{3}$ & $\mathbf{2 \%}$ \\
\hline 4 & Situasi & & & 6 & $\mathbf{6}$ & $\mathbf{3 , 4 \%}$ \\
\hline 5 & Humor & & & 1 & $\mathbf{1}$ & $\mathbf{1 \%}$ \\
\hline 6 & Kemampuan & 2 & 4 & 3 & $\mathbf{6}$ & $\mathbf{3 , 4 \%}$ \\
\hline 7 & Teknologi & & 7 & 13 & $\mathbf{3 2}$ & $\mathbf{1 8 , 4 \%}$ \\
\hline 8 & Keakraban & 12 & 6 & & $\mathbf{6}$ & $\mathbf{3 , 4 \%}$ \\
\hline 9 & Hubungan & & 75 & 58 & 173 & 173 \\
\hline
\end{tabular}

Dari tabel tersebut dapat peneliti simpulkan bahwa faktor terjadinya alih kode yang paling sering muncul yaitu faktor penutur dengan persentase sebanyak $51 \%$ dan yang paling jarang muncul yaitu pada faktor humor pembicaraan dalam wujud peralihan 
kode intersentential dengan persentase sebanyak $1 \%$ dan juga faktor ini berwujud peralihan kode hanya dalam intersentensial. Untuk lebih jelasnya dapat dilihat pada ringkasan data dibawah ini.

\section{Fungsi Alih Kode}

Penelitian ini akan mendeskripsikan fungsi terjadi alih kode dalam percakapan lewat WhatApp oleh mahasiswa KNB yang sedang berkuliah di UNS. Maka terdapat beberapa fungsi yang melatarbelakangi adanya alih kode, diantaranya: 1) untuk menjalin keakraban dengan mitra tutur, 2) untuk menghormati lingkungan tempat tinggal atau budaya, 3) untuk memudahkan komunikasi, 4) sebagai serapan dalam hal teknologi, 5) untuk memperkaya kemampuan berbagai bahasa, 6) untuk mengingatkan, 7) untuk merespon pertanyaan, 8) untuk mengawali ,menengahan, atau mengakhiri tuturan, 9) untuk lebih menekankan maksud penutur, 10) sebagai ajakan, 11) untuk mengubah situasi formal ke informal, 12) utuk percepsi, 13) sebagai ekspresi penutur, 14) untuk mengutip percakapan orang lain, 15) bercanda, 16) untuk spisifik mitra tutur, 17) untuk meminta tolong sesuatu, 18) untuk menjelaskan, dan 19) berubah topik. Fungsi alih kode tersebut tampak pada tabel berikut.

Tabel 6. Fungsi Yang Melatarbelakangi Alih Kode

\begin{tabular}{|c|c|c|c|c|c|c|}
\hline \multirow[b]{2}{*}{ No } & \multirow[b]{2}{*}{$\begin{array}{l}\text { Fungsi terjadi alih } \\
\text { kode }\end{array}$} & \multicolumn{3}{|c|}{ Alih kode } & \multirow[b]{2}{*}{$\sum$} & \multirow[b]{2}{*}{$\%$} \\
\hline & & Tag & Intrasentential & Intersentential & & \\
\hline 1 & $\begin{array}{l}\text { Mengakraban sesama } \\
\text { mitra tutur }\end{array}$ & 11 & 7 & 12 & 30 & $17,3 \%$ \\
\hline 2 & $\begin{array}{l}\text { Menghormati } \\
\text { lingungan tempat } \\
\text { tinggal atau budaya }\end{array}$ & & 28 & & 28 & $16,2 \%$ \\
\hline 3 & $\begin{array}{l}\text { Mudah dalam } \\
\text { pengucapan atau } \\
\text { meyatakan. }\end{array}$ & & 26 & 9 & 33 & $20.2 \%$ \\
\hline 4 & $\begin{array}{l}\text { Memperlukan dalam } \\
\text { teknologi }\end{array}$ & & 4 & 2 & 6 & $3,4 \%$ \\
\hline 5 & $\begin{array}{l}\text { Memperkayakan } \\
\text { kemampuan } \\
\text { berbahasa dari satu } \\
\text { atau dua bahasa }\end{array}$ & 2 & 1 & 3 & 6 & $3,4 \%$ \\
\hline 6 & Mengingatkan & & & 1,280 & 2 & $1,2 \%$ \\
\hline 7 & Merespon pertanyaan & 7 & & 5 & 12 & $7 \%$ \\
\hline 8 & $\begin{array}{l}\text { Mengawali, menyisipi } \\
\text { di tengah, atau }\end{array}$ & 16 & & & 16 & $9 \%$ \\
\hline
\end{tabular}




\begin{tabular}{|c|c|c|c|c|c|c|}
\hline & $\begin{array}{l}\text { mengakhiri tuturan } \\
\text { saja }\end{array}$ & & & & & \\
\hline 9 & Menekankan & 3 & 1 & 1 & 5 & $3 \%$ \\
\hline 10 & Mengajak & 1 & 1 & 1 & 4 & $2,3 \%$ \\
\hline 11 & $\begin{array}{l}\text { Berubah situasi } \\
\text { formal ke informal }\end{array}$ & & & 6 & 6 & $3,4 \%$ \\
\hline 12 & Mempercepsikan & & 2 & & 2 & $1,2 \%$ \\
\hline 13 & Mengekspresi & & & 8 & 8 & $5 \%$ \\
\hline 14 & $\begin{array}{l}\text { Mengutip percakapan } \\
\text { orang lain }\end{array}$ & & & 1 & 1 & $0,5 \%$ \\
\hline 15 & bercanda & & 1 & 2 & 3 & $1,7 \%$ \\
\hline 16 & $\begin{array}{l}\text { Menspisifik mitra } \\
\text { tutur }\end{array}$ & & 1 & & 1 & $0,5 \%$ \\
\hline 17 & $\begin{array}{l}\text { Meminta tolong } \\
\text { sesuatu }\end{array}$ & & 3 & 1 & 4 & $2,3 \%$ \\
\hline 18 & Menjelaskan & & & 2 & 2 & $1,2 \%$ \\
\hline 19 & Mengubah topik & & & 2 & 2 & $1,2 \%$ \\
\hline & Total & 40 & 75 & 58 & 128 & $100 \%$ \\
\hline
\end{tabular}

Dari tabel tersebut terlihat jelas bahwa fungsi terjadi alih kode yang paling sering muncul dalam dialog percakapan lewat WhatsApp oleh mahasiswa KNB adalah untuk mudah dalam mengucapkan yaitu 20,2\% dan fungsi alih kode yang paling jarang digunakan adalah 1) mengutip percakapn orang lain, dan 2) menspisifik mitra tutur terdapat $0,5 \%$ dalam percakapan.

\section{Simpulan}

Simpulan hasil penelitian tentang "Penggunaan Alih Kode Dalam Percakapan Pada Jaringan Whatsapp Oleh Mahasiswa KNB Yang Berkuliah di Universitas Sebelas Maret" ini merupakan jawaban dari tiga masalah yang dikaji. Masalah penelitian meliputi (1) Apakah jenis alih kode yang digunakan via WhatsApp oleh mahasiswa KNB dari UNS (2) Faktor- -faktor apa yang menyebabkan mahasiswa KNB dari UNS menggunakan alih kode (3) Apakah fungsi alih kode dalam percakapan via WhatsApp oleh mahasiswa KNB dari UNS. Pada rumusan masalah yang pertama yakni untuk menjawab pertanyaan mengenai jenis-jenis alih kode yang digunakan via WhatsApp oleh mahasiswa KNB dari UNS. Peneliti menemukan beberapa jenis alih kode yang digunakan oleh mahasiswa KNB, ada tiga jenis antara lain, 1) alih kode jenis antar kalimat (Intersentencial switching) yaitu jenis alih kode yang digunakan oleh penutur dari bahasa satu ke bahasa lain dalam bentuk klausa atau kalimat 2) alih kode jenis 
intrakalimat (Intrasentencial switching) yaitu jenis alih kode yang digunakan oleh penutur dari bahasa satu ke bahasa lain dalam kata atau frasa 3) alih kode jenis tag (tag switching) yaitu jenis alih kode yang digunakan oleh penutur dari bahasa satu ke bahasa lain dalam bentuk ekspresi, seruan dan partikel-partikel dalam ujaran. Dari beberapa alih kode yang terurai diatas, jenis alih kode yang paling dominan digunakan dalam jaringan WhatsApp adalah jenis alih kode intrasentential dari bahasa Inggris ke bahasa Indonesia. Jumlah persentase dari jenis alih kode intrasentensial adalah $43 \%$ dari satuan lingual berupa kata dan frasa yang terdapat pada tuturan penutur ataupun mitra tutur. Jenis alih kode yang paling sedikit digunakan oleh mitra tutur adalah jenis alih kode intersentensial dengan jumlah persentase 34\%. Jenis intersentensial ini muncul pada tuturan penutur dalam bentuk klausa dan kalimat, sedangkan jenis alih kode tag mempunyai persentase sebanyak $23 \%$ dari hasil tuturan dari penutur yakni mahasiswa KNB yang berkuliah di UNS. Rumusan masalah yang kedua yakni faktor-faktor yang menyebabkan mahasiswa KNB dari UNS menggunakan alih kode.

Pada penelitian telah dianalisis data-data yang diperoleh peneliti dan beberapa faktor yang menyebabkan mahasiswa KNB dari UNS menggunakan alih kode antara lain, (1) penutur, yang dengan sengaja beralih kode terhadap mitra tutur untuk dapat mengutarakan maksud pembicaraannya kepada mitra tutur. Oleh karena itu penutur beralih kode sesuai dengan kebutuhan. Tujuannya adalah agar mitra tutur dapat merespon pembicaraan atau maksud dari penutur (2) mitra tutur, yang merupakan salah satu faktor penting dalam berkomunikasi. Alih kode juga dapat muncul pada tuturan dari mitra tutur karena apabila penutur mempergunakan bahasa yang bbukan bahasa kesehariannya, maka mitra tutur akan merespon tuturan dari penutur dengan cara beralih kode (3) topik pembicaraan, Topik pembicaraan merupakan faktor terjadinya alih kode. Topik pembicaraan yang bersifat formal biasanya diungkapkan dengan ragam baku dan pokok pembicaraan yang bersifat informal disampaikan dengan bahasa nonbaku (4) situasi, apabila situasi dalam percakapan sedang berlangsung bersama seseorang yang bukan mempunyai latar belakang yang sama terkadang situasi itu sangat penting dalam berkomunikasi sehingga situasi itu juga menanda identitas seseorang dalam berbicara. Situasi mempengaruhi seseorang untuk beralih kode agar komunikasi berjalan dengan lancar. (5) Humor, merupakan sesuatu yang bersifat lucu yang dapat menggelikan hati atau rasa geli bagi yang mendengar maupun melihatnya. Penutur ataupun mitra tutur 
yang mempunyai rasa humor terkadang akan beralih kode menggunakan bahasa lain dalam percakapan. (6) Kemampuan adalah seseorang menguasai sesuatu yang berlebih dari yang lain, seperti seseorang mempunyai bahasa yang berlebih. Kemampuan seseorang untuk mempergunakan bahasa yang secara sosial dapat diterima. Kemampuan juga dapat diukur melalui pengetahuan bidang bahasa yaitu mengerti pada kosakata, melengkapi kalimat, hubungan kata, dan wacana itu dapat menjadi penyebab alih kode pada tuturan, maka berikut ini akan dicontohi pada kemampuan tersebut (7) teknologi, Teknologi adalah segala sesuatu yang berkaitan dengan penggunaan alat bantu untuk memproses dan mentransfer data dari perangkat yang satu ke lainnya. Teknologi merupakan kebutuhan bagi semua oarng dalam menggunakan karena itu sangat efektif bagi manusia yang menggunakannya untuk bermunikasi dalam sehari-hari. (8) keakraban ketika seseorang bertemu dan saling mengenal maka rasa perhatian sesama mereka akan terjadi. Sama seperti teman-teman KNB yang datang dari berbeda negara tetapi mereka saling mengenal dan bantu sesama lain maka keakraban bisa terjadi antara mereka. Sehingga ketika mereka berbicara suasana lebih ke santai dan senang. (9) hubungan dapat terjadi alih kode ketika hubungan antara dua peristiwa saling mengenal dan mengetahui jarak kehormatan sesama lain.

Faktor terjadinya alih kode yang paling sering muncul yaitu faktor penutur dengan persentase sebanyak $51 \%$ dan yang paling jarang muncul yaitu pada faktor humor pembicaraan dalam wujud peralihan kode intersentential dengan persentase sebanyak $1 \%$ dan juga faktor ini berwujud peralihan kode hanya dalam intersentensial. Rumusan masalah yang ketiga merupakan fungsi-fungsi alih kode yang digunakan mahasisa KNB dalam percakapan. Beberapa fungsi yang telah ditemukan oleh peneliti dalam hal ini antara lain: 1) untuk memperlancarkan kemampuan bahasa Indonesia 2) untuk menjalin keakraban dengan mitra tutur, 3) untuk menghormati lingungan tempat tinggal atau budaya, 3) untuk memudahkan komunikasi, 4) sebagai serapan dalam hal teknologi, 5) untuk memperkaya kemampuan berbagai bahasa, 6) untuk mengingatkan, 7) untuk merespon pertanyaan, 8) untuk mengawali ,menengahan, atau mengakhiri tuturan, 9) untuk lebih menekankan maksud penutur, 10) sebagai ajakan, 11) untuk mengubah situasi formal ke informal, 12) utuk percepsi, 13) sebagai ekspresi penutur, 14) untuk mengutip percakapan orang lain, 15) bercanda, 16) untuk spisifik mitra tutur, 17) untuk meminta tolong sesuatu, 18) untuk menjelaskan, dan 19) berubah topik. 
Fungsi terjadi alih kode yang paling sering muncul dalam dialog percakapan lewat WhatsApp oleh mahasiswa KNB adalah untuk mudah dalam mengucapkan yaitu 20,2\% dan fungsi alih kode yang paling jarang digunakan adalah 1) mengutip percakapn orang lain, dan 2) menspisifik mitra tutur terdapat $0,5 \%$ dalam percakapan.

\section{Referensi}

Chaer, A., \& Agustina, L. (2010). Sosiolinguistik perkenalan awal. Jakarta: Rineka Cipta.

Chaer, A. (2012). Linguistik umum. Catakan keempat. Jakarta: Rineka Cipta.

Djajasudarma. (2010). Metode linguistik: ancangan metode penelitian dan kajian. Bandung: PT. Refika Aditama.

Harahap, N. (2008). Analisis pragmatik wacana iklan surat kabar. Medan: Universitas Sumatra Utara Medan.

Hendar, dan Yunita, T.S. (2012). "Penggunaan alih kode dalam program siaransal (Shine after lunch) di radio ardan 105.9 FM Bandung”, Universitas Widyatama Bandung, No. 204A Bandung Press.

Holmes, J. (2001). An Introduction to Sociolinguistics. New York: Longman.

Hymes, D. (1972). The Ethnography of Speaking.http://www.ebooklibrary.org/articles/dell_hymes. (akses pada 13/2/2016 pukul 7.08 am.)

Kridalaksana, H. (2011). Kamus Linguistik (edisi keempat). Jakarta: Gramedia Pustaka Utama.

Maricar, F. (2014). The Influence Factor of Ternate Language Shift in Ternate City.International Research Journal of Arts \& Humanities (IRJAH), Vol.5, issue 1, January 2016. Index Copernicus value (2013): 6:14.

Mutmainah, Y. (2008). "Pemilihan kode dalam Masyarakat Dwibahasa: Kajian Sosiolinguistik Pada Masyarakay Jawa di Kota Bantang Kalimantan Timur.” Semarang. Universitas Diponoegoro.

Nababan, P. W. J. (1993). Sosiolinguistik: suatu pengantar. Jakarta: Gramedia.

Nahdiah, N. (2012). “Alih kode penutur L2 bahasa Jepang dalam tweet.” Jakarta: Universitas Indonesia.

Nirmala, D. (2012). "Fungsi pragmatik metafora dalam wacana surat pembaca berbahasa Indonesia”. Semarang: Universitas Diponoegoro. 
Poejosoedarmo, S. (1978). Kode dan alih kode di dalam Widyaparwa 15. Yogyakarta : Balai Pendidikan Bahasa.

Rahardi, K. (2001). Sosiolinguistik, kode dan alih kode. Yokyakarta: Pustaka Pelajar.

Romaine, S. (1989). Language in society: an introduction to sociolinguistics. Published. London: Longman. . (1994). Language in society: an introduction to sociolinguistics. New York: Oxford University Press.

Rusdiah. (2014). Code-switching serves a euphemis. International Research Journal of Arts \& Humanities (IRJAH), Vol.5, issue1, January 2016. Index Copernicus value (2013) 6:14 Impact factor (2014) 5:611 ISSN (online):2319-7064.

Santosa, R. (2012). Metode penelitian kualitatif kebahasaan. Draf buku. Surakarta: Fakultas Sastra dan Seni Rupa UNS.

Suandi, I. N. (2014). Sosiolinguitik. Yogyakarta: Graha Media.

Sumarsono. (2008). Sosiolinguistik. Yogyakarta: Sabda.

Sutopo, H.B. (2002). Metode penelitian kualitatif dasar teori dan terapannya dalam penelitian. Surakarta: Surakarta.

Suwito. (1983). Sosiolinguistik: teori dan problema. Sukarta: Kenarry Offset.

Vinansis, M. R. (2011). "Alih kode dan campur kode bahasa Jawa dalam rapat ibu-ibu PKK di Kepatihan Kulon Surakarta.” Surakarta: Universitas Sebelas Maret.

Yim, O., \& Bialystok, E. (2012). Degree of conversational code-switching enhances verbal task switching in Cantonese-English bilinguals. Bilingualism: Language and Cognition. National Science and Research Council, Canada (NSER), vol. 15 (no.4), hlm.873-883.

http://www.uns.ac.id/Universitas Sebelas Maret (akses pada 9/1/2016 pukul 10:03 am.)

https://id.wikipedia.org/wiki/WhatsApp. (akses pada 9/1/2016 pukul 10:01 am.)

https://nagabiru86.wordpress.com/2009/06/12/data-sekunder-dan-data-prime.(akses pada $\quad 1 / 18 / 2016$ pukul 6:50 $\mathrm{pm}$.)

http://shantycr7.blogspot.co.id/2013/06/menggunakan-dan-menilai-datasekunder.html.(akses pada 1/18/2016 pukul 6:53 PM) 